\title{
Social media; resolving tunnel vision in practicing medicine
}

Fatemeh Hosseini Kordmahaleh ${ }^{1}$, Alaleh Rouhipour ${ }^{1}$, Sahar Mirbaha ${ }^{2}$, Alireza Baratloo ${ }^{3}$

\author{
${ }^{1}$ M.D., Specialist Physician, Clinical Research Developmental Center, Shohadaye Tajrish Hospital, Shahid Beheshti \\ University of Medical Sciences, Tehran, Iran \\ ${ }^{2}$ M.D., Assistant Professor, Department of Emergency Medicine, Faculty of Medicine, Shahid Beheshti University \\ of Medical Sciences, Tehran, Iran \\ ${ }^{3}$ M.D., Associate Professor, Department of Emergency Medicine, Faculty of Medicine, Tehran University of \\ Medical Sciences, Tehran, Iran
}

\section{Type of article: Original}

\begin{abstract}
Background: With the emergence of social media, physicians who use social media, including emergency medicine physicians, have shared their experiences with their colleagues instead of working alone and keeping their experiences to themselves.

Objective: This study aimed to evaluate the rate and type of use of electronic online sources and social media, in order to improve learning and education among emergency medicine residents.

Methods: This was a cross-sectional study carried out from September 2015 until August 2016 on emergency medicine residents of two main medical universities of Tehran, Iran. A questionnaire was prepared by reviewing the existing studies and asking emergency medicine professors inside and outside Iran for opinions. Census sampling method was applied and all emergency medicine residents were included. The gathered data were analyzed using statistical tests of chi square, Independent-samples t-test and Pearson's correlation coefficient via SPSS version 21.

Results: Seventy three residents with the mean age of $34.2 \pm 5.2$ years participated in this study ( $60.3 \%$ female). Smart phone is the most important tool they use for connecting to the Internet. About $30 \%$ use the Internet for about 1-2 hours a day. In half of these participants less than $25 \%$ of this time is spent on something related to their academic field of study. The correlation of sex $(p=0.034)$ and age $(p=0.049)$ with extent of using social media related to the academic field of study were significant. Other analytical analyses were not statistically significant $(\mathrm{p}>0.05)$.

Conclusion: In summary, the findings of current study showed that despite sufficient access to proper technology, use of social media and online sources by high majority of the studied EM residents regarding improvement of their learning and educational level is very limited.

Keywords: Social media; Emergency medicine; Smartphone; Medical education
\end{abstract}

\section{Introduction}

\subsection{Background}

Moving towards being knowledge-based in the world we live in, reaching competitive superiority in organizations given rise to knowledge sharing as an important category. From the end of the last century, various tools and scientific products $(1,2)$ for sharing knowledge have been developed and people can use them easily to reach a more reciprocal cooperation. Social networks are among the tools that have enabled people from all walks of life, to announce and exchange ideas, and they act as a suitable medium for collaboration with others and provide the required ground for sharing knowledge and information online. With social media appearing, physicians, including emergency medicine physicians, have shared their experiences with their colleagues instead of working alone and keeping their experience to themselves $(3,4)$.

\section{Corresponding author:}

Associate Professor Dr. Alireza Baratloo, Department of Emergency Medicine, Sina Hospital, Tehran University of Medical Sciences, Tehran, Iran. Tel: +98.9122884364, Email: arbaratloo@sina.tums.ac.ir

Received: January 17, 2017, Accepted: August 23, 2017, Published: January 2018

iThenticate screening: August 14, 2017, English editing: December 12, 2017, Quality control: December 15, 2017

(C) 2018 The Authors. This is an open access article under the terms of the Creative Commons Attribution-NonCommercialNoDerivs License, which permits use and distribution in any medium, provided the original work is properly cited, the use is non-commercial and no modifications or adaptations are made. 


\subsection{Statement of problem and study logic}

Although physicians face challenges in adapting new technologies, using such implements will certainly bring about many opportunities for communication and improving the functionality of their performance. There are some studies that have been carried out both inside and outside Iran in this regard. They were indicative of the increasing attention of researchers to web technology and social media (5-8). In a research conducted with Babson Survey Research Group, it was reported that more than $60 \%$ of all participant faculty had used social media during a course (9). Following a systematic review, Cheston et al. claimed that using social media in medical education is an emerging field of scholarship that requires further research (10). Although investigations regarding this topic have been conducted around the world, use of social media in Iran is accompanied with some special barriers and is somewhat distinctive compared with most of the other developed and developing countries. Facebook, Twitter and YouTube are considered as illegal networks, and are being filtered by the Iranian government. Therefore, this topic continues to be infertile in Iranian society. Eslaminejad et al. assessed faculty readiness for implementing e-learning, and concluded that educational and technical improvement are still required in this regard (11). Ashrafi-rizi et al. conducted a survey on the rate of media literacy among Isfahan University of Medical Sciences' students and concluded that their media literacy level was higher than average, but they did not have enough skills in membership and subscription in useful society networks or skills in tracking news (12). In another study, Sari-Motlagh et al. created telegram groups as a resource for urologists to facilitate their communication and eliminate the limitation resulted by time barriers or geographic distance. They claimed that such an e-learning tool may be useful in terms of improving clinical knowledge and narrowing the gap between high-quality evidence and clinical practice in developing countries such as Iran (13). Considering such studies, it seems that conducting research on the topic of social media is still required in terms of knowledge and attitude of different Iranian societies that will be followed up later by performing research on their skills. Considering the high volume of information distributed in the virtual world, which is update by the minute, and the fact that the emergency medicine residents apparently spend a considerable portion of the day using the Internet, this study may enable them to use these rich sources of information by evaluating the current status of their awareness of this potential equipment. Therefore, gaining information regarding the baseline condition of this statistical population can make possible both short and longterm programming, in order to improve the situation. To the best of our knowledge, there has not been a study evaluating the rate and type of use of electronic online sources and social networks to improve learning and education among emergency medicine residents. Therefore, the present study has attempted to assess this important issue.

\section{Material and Methods}

\subsection{Study design and participants}

The present study was a cross-sectional one, carried out from the beginning of September 2015 until the end of August 2016 in Tehran University of Medical Sciences (TUMS) and Shahid Beheshti University of Medical Sciences (SBMU), Tehran, Iran. Census sampling method was applied in the current study. All students of TUMS and SBMU who were in an emergency medicine residency program over the course of this study were included. Not giving informed consent for participating in the study and not completely filling the questionnaire were considered as exclusion criteria of the present study.

\subsection{Definition}

Social media: Computer-mediated technology that facilitates the creation and sharing of information, ideas, career interests and other forms of expression via virtual communities and networks.

Valid online source: It is defined as the online source, including websites or social media, officially belonging to or affiliated to a global, multinational academic medicine society from around the world.

\subsection{Data gathering}

To determine the rate and type of using online electronic sources and social media in order to improve learning and education among emergency medicine residents, a questionnaire was prepared by reviewing the existing studies and asking emergency medicine professors inside and outside Iran for opinions. The questionnaire consisted of demographic data of the residents and questions regarding their use of online electronic sources and social networks. The reliability of the questionnaire was determined via internal consistency assessment (Cronbach's alpha $=0.79$ ). The validity was also measured via consulting 10 emergency medicine specialists working as faculty members, and content validity ratio (CVR) was equal to 0.68 . The researcher attended all the hospitals affiliated with the mentioned universities and gave the questionnaire to emergency medicine residents after providing initial 
explanations regarding how to answer them and obtaining informed consent, and gathered them after they were filled.

\subsection{Statistical analysis}

After gathering the required data, the findings were entered to IBM $\odot$ SPSS $\odot$ Statistics version 21 (IBMC Corp., Armonk, NY, USA) and were analyzed using descriptive statistics of frequency and percentage, mean \pm standard deviation (SD), and also statistical tests of chi square or Fisher's exact tests. Multivariate logistic regression analysis was applied with the aim of calculating odds ratio (OR) of each significant factor. P-value lower than 0.05 was considered significant.

\subsection{Ethical considerations}

This study was carried out after obtaining the approval and license from the ethics committee of Shahid Beheshti University of Medical Sciences. Obtaining written informed consent from all the participating residents after completely explaining the benefits of participating in the study was the first and most important step for taking part in this study. All the questionnaires were anonymous and keeping all the residents' data confidential in the questionnaires was among other ethical considerations in this project. In addition, all the data are reported in groups and anonymously. Participating in this project did not cost the participants anything.

\section{Results}

\subsection{Descriptive findings}

From 178 eligible EM residents, just 73 residents participated and the others were refused. Participation rate was about $41.0 \%$. The mean age of participants was $34.2 \pm 5.2$ (range: $26-47$ ) years and $60.3 \%$ were female. Table 1 shows the baseline characteristics and demographic data of the study participants. Most residents use translated books for studying their textbooks and if they encounter a question or confusion they will refer to the respective textbook.

Table 1. Demographic data and baseline characteristics of the studied population

\begin{tabular}{|c|c|c|c|}
\hline \multicolumn{2}{|l|}{ Variable } & $\mathrm{n}$ & $\%$ \\
\hline \multirow[t]{2}{*}{ Sex } & Female & 44 & 60.3 \\
\hline & Male & 29 & 39.7 \\
\hline \multirow[t]{5}{*}{ General practitioner graduation year } & $<1990$ & 7 & 9.6 \\
\hline & $1990-95$ & 12 & 16.4 \\
\hline & $1996-2000$ & 26 & 35.6 \\
\hline & 2001-05 & 25 & 34.3 \\
\hline & $>2005$ & 3 & 4.1 \\
\hline \multirow[t]{2}{*}{ University name } & Shahid Beheshti University of Medical Sciences & 43 & 58.9 \\
\hline & Tehran University of Medical Sciences & 30 & 41.1 \\
\hline \multirow[t]{3}{*}{ Level of residency } & $1^{\text {st }}$ & 26 & 35.6 \\
\hline & $2^{\text {nd }}$ & 25 & 34.3 \\
\hline & $3^{\text {rd }}$ & 22 & 30.1 \\
\hline \multirow[t]{3}{*}{ Main source of daily study } & Summary & 14 & 19.2 \\
\hline & Translation & 34 & 46.6 \\
\hline & Textbook & 25 & 34.2 \\
\hline \multirow[t]{2}{*}{ Search training course } & Yes & 20 & 27.4 \\
\hline & No & 53 & 72.6 \\
\hline \multirow[t]{5}{*}{ Main search engine } & Yahoo & 2 & 2.7 \\
\hline & Google & 29 & 39.7 \\
\hline & Google scholar & 13 & 17.8 \\
\hline & PubMed & 27 & 37.1 \\
\hline & Other & 2 & 2.7 \\
\hline \multirow[t]{4}{*}{ Newsletters subscription } & Medscape & 48 & 65.8 \\
\hline & EM case & 5 & 6.85 \\
\hline & Other & 10 & 13.7 \\
\hline & None & 10 & 13.7 \\
\hline
\end{tabular}


Most cases have not participated in the search training courses and a significant number use Yahoo and Google for searching instead of specialized search engines such as Google Scholar. Table 2 indicates the type and rate by which the study participants use the Internet for studying. Based on the obtained results, most participants have stated that smart phone is the most frequent tool they use for connecting to the Internet and the most important use of the Internet for them is receiving the latest news. About $30 \%$ of the participants use the Internet for about 1-2 hours a day. In half of these participants, less than $25 \%$ of this time is spent on something related to their academic field of study. However, 48 (65.8\%) of them have registered themselves on Medscape website and receive its newsletters. Table 3 is dedicated to type and rate of social media usage among the study participants. Despite more than half of study participants being members of at least one social media, $59(80.8 \%)$ of them did not have a correct definition of social media. Nevertheless, 54 (73.9\%) of the participants acknowledged the possibility of using social media for improving their educational level. About $30 \%$ of participants spend less than 1 hour a day browsing social media. In more than half of them, less than $25 \%$ of their time on the Internet is related to their academic field of study.

Table 2. Type and rate of using the Internet among the study participants

\begin{tabular}{|l|l|l|l|}
\hline Variable & $\mathrm{n}$ & $\%$ \\
\hline Internet connection tool & Smart phone & 53 & 72.6 \\
\cline { 2 - 4 } & Tablet & 19 & 26.1 \\
\cline { 2 - 4 } & Lap top & 10 & 13.7 \\
\hline \multirow{5}{*}{ Goal to use new technology } & News & 53 & 72.6 \\
\cline { 2 - 4 } & Friend connection & 27 & 36.9 \\
\cline { 2 - 4 } & Recreation & 21 & 28.8 \\
\hline Internet use (hour/day) & $<1$ & 10 & 13.7 \\
\cline { 2 - 4 } & $1-2$ & 26 & 35.6 \\
\hline & $2-3$ & 15 & 20.5 \\
\hline & $3-4$ & 11 & 15.1 \\
\hline & $>4$ & 11 & 15.1 \\
\hline Related to your academic field of study (\%) & $<25$ & 42 & 57.5 \\
\cline { 2 - 4 } & $25-50$ & 18 & 24.7 \\
\cline { 2 - 4 } & $50-75$ & 9 & 12.3 \\
\hline & $>75$ & 4 & 5.5 \\
\hline
\end{tabular}

Table 3. Type and rate of using social pages among the study participants

\begin{tabular}{|l|l|l|l|}
\hline Variable & $\mathrm{n}$ & $\%$ \\
\hline Social media & Facebook & 31 & 42.5 \\
\cline { 2 - 4 } & Instagram & 31 & 42.5 \\
\cline { 2 - 4 } & Google + & 15 & 20.5 \\
\cline { 2 - 4 } & LinkedIn & 13 & 17.8 \\
\cline { 2 - 4 } & Twitter & 4 & 5.5 \\
\hline \multirow{5}{*}{ Visiting social media (hour/day) } & $<1$ & 30 & 41.1 \\
\cline { 2 - 4 } & $1-2$ & 19 & 26.1 \\
\cline { 2 - 4 } & $2-3$ & 11 & 15.1 \\
\cline { 2 - 4 } & $3-4$ & 5 & 6.8 \\
\cline { 2 - 4 } & $>4$ & 8 & 10.9 \\
\hline Assessing validity of a topic presented in social media & Resource based & 39 & 53.4 \\
\cline { 2 - 4 } & Friend based & 6 & 8.2 \\
\cline { 2 - 4 } & Comparing & 26 & 35.6 \\
\cline { 2 - 4 } & All reliable & 2 & 2.7 \\
\hline Related to academic field of study (\%) & $<25$ & 45 & 61.7 \\
\cline { 2 - 4 } & $25-50$ & 17 & 23.3 \\
\cline { 2 - 4 } & $50-75$ & 3 & 4.1 \\
\hline & $>75$ & 8 & 10.9 \\
\hline
\end{tabular}




\subsection{Analytical findings}

Table 4 depicts the relationship of the main source for daily study, registration on scientific websites, extent of daily Internet use, extent of using the Internet in relation to academic field of study, extent of using social media and extent of using social media related to their academic field of study with variables such as age, sex, time of graduation as a general practitioner, residency level, and the current university in which they are studying. Based on the findings analyzed by chi square test, the correlation between sex and extent of social media usage ( $\mathrm{p}=0.034$; OR: 18.7) and also correlation between age and extent of social media usage related to the academic field of study $(\mathrm{p}=0.049$; OR: 13:2) were significant. It means that the lower age female emergency medicine residents are more interested and involved with using social media and the Internet for improving their educational level than the other ones. Other analytical analyses were not statistically significant $(\mathrm{p}>0.05)$.

Table 4. P-values related to analytical analyses of baseline and demographic variables of the study participants

\begin{tabular}{|l|l|l|l|l|l|}
\hline Variables & Age & Sex & $\begin{array}{l}\text { Level of } \\
\text { residency }\end{array}$ & $\begin{array}{l}\text { Year of general graduation } \\
\text { practitioner }\end{array}$ & $\begin{array}{l}\text { Current } \\
\text { university }\end{array}$ \\
\hline Main source of daily study & 0.564 & 0.768 & 0.325 & 0.188 & 0.079 \\
\hline Subscription for newsletters & 0.672 & 0.158 & 0.431 & 0.090 & 0.727 \\
\hline Daily Internet use & 0.648 & 0.718 & 0.110 & 0.646 & 0.195 \\
\hline $\begin{array}{l}\text { Internet related to academic } \\
\text { field }\end{array}$ & 0.723 & 0.094 & 0.363 & 0.949 & 0.124 \\
\hline Daily social media use & 0.538 & 0.034 & 0.098 & 0.573 & 0.374 \\
\hline $\begin{array}{l}\text { Social media related to } \\
\text { academic field }\end{array}$ & 0.049 & 0.760 & 0.053 & 0.915 & 0.158 \\
\hline
\end{tabular}

\section{Discussion}

Although a high majority of the studied emergency medicine residents in the current study have sufficient access to the world's up to date technology for connecting to the Internet 24 hours a day and 7 days a week, they are not familiar with valid online sources in their field of academic study, and their use of social networks and the Internet for improving their learning and education is very limited. A 2012 study by Payne conducted a survey in England to identify the extent to which junior doctors and medical students own smartphones and use them to enhance their clinical activities (14). Based on the findings of our study compared with the Payne study, accessibility of studied participants to the suitable tools such as up to date smartphones and tablets, and using medical related applications such as Medscape, are equivalent with developed countries. Interestingly, frequency and daily use of medical related apps and online source were almost the same in both ours and Payne's studies. A 2011 study by Bosslet aimed to determine the extent of using online social media, interacting with patients in online social networks, and viewpoints regarding online social networks among medicine students, residents, and specialists. The general response rate was only $16 \%$. They reported that $79.4 \%$ of the residents used online social networks (15). It seems that despite the low participation rate in the Bosslet study, more residents were involved with social media compared to what we got in our study. A 2014 study by Keller, evaluated the extent that public health specialists used social media. In this study, a survey was held in the health faculty of Johns Hopkins University, Baltimore, Maryland, USA. All the accessible specialists were asked about use of social media. This study revealed that a small minority of health specialists are active in these social spaces, while many of them, either with or without intention, are opposed to professional exchanges in these virtual social spaces. Social media, in the eyes of most participants, was a tool to distribute information rather than gaining it. (6). Compared with the Keller study results, participation rate was higher in our study (19.8\% vs. $41.0 \%)$. The statistical values regarding the extent of use of social media are somehow the same. Although most of participants of both studies agreed that social media was important for distributing data, fewer in the Keller study than our study expressed that social media was beneficial for professional and occupational advances $(23.8 \%$ vs. $73.9 \%)$. A 2014 study by Brown introduced the status and national profile of Australian physicians' viewpoints regarding the use of online social media and its rate. They mentioned that many of the participants $(65.8 \%)$ had doubts about using social media and online communications and they were worried about public access and legal concerns. They reported that despite the rapid growth of online and social media, physicians had different points of view and methods regarding the proper style of communication on the Internet. (7). Compared with the Brown study results, participation rate was higher in our study (12.5\% vs. $41.0 \%)$. Like our study, most participants had personal use of social media. Surprisingly, legal concerns were considered by the participants in both studies, although with different aspects regarding their nationality. Comparing the results of such studies in countries like the US and Australia with Iran can be fairly done because training, accessibility, quality of Internet and legal aspects are not similar. Considering such important points, as it was mentioned earlier, primarily 
the accessibility, knowledge and attitude of different Iranian societies should be compared with other countries, then with considering the differences, more investigation regarding people skills in terms of using social media should be performed. Establishment and application of social media policies based on the current laws in each country has been recommended $(16,17)$. Regarding the study limitation, lack of cooperation among some residents and not participating in this project were among the major limitations of this study. Unfortunately, despite in-person consultations and explaining the benefits of taking part in the study for educating and spreading knowledge, aiming to improve the level of awareness, did not lead to a high rate of cooperation among the residents.

\section{Conclusions}

In summary, the findings of the current study showed that despite sufficient access to proper technology, use of social media and online sources by a high majority of the studied EM residents regarding improvement of their learning and educational level, is very limited. It is likely that encouraging medical students and EM residents to use social media and providing sufficient education in this field are still necessary. It is suggested that educational planners and medical students' mentors pay more attention to potential applications of such resources. Performing supplementary researches regarding the accessibility, knowledge and attitude of different Iranian societies followed by more investigation on people skills in terms of using social media, can be a considerable direction for future research on this topic.

\section{Acknowledgments:}

We would like to express our special thanks to the faculty members and residents of the Emergency Department of Tehran and Shahid Beheshti Universities of Medical Sciences. This study was conducted with a grant from the Clinical Research Developmental Center of Shohadaye Tajrish Hospital, Tehran, Iran (ID: 6822). This study was a part of Dr. Fatemeh Hosseini Kordmahaleh's thesis for Emergency Medicine Residency at Shahid Beheshti University of Medical Sciences, Tehran, Iran.

\section{Conflict of Interest:}

There is no conflict of interest to be declared.

\section{Authors' contributions:}

All authors contributed to this project and article equally. All authors read and approved the final manuscript.

\section{References:}

1) Penuel WR, Sussex W, Korbak C, Hoadley C. Investigating the potential of using social network analysis in educational evaluation. Am J Eval. 2006; 27(4): 437-51. doi: 10.1177/1098214006294307.

2) Mangold WG, Faulds DJ. Social media: The new hybrid element of the promotion mix. Bus Horiz. 2009; 52(4): 357-65. doi: 10.1016/j.bushor.2009.03.002.

3) Ahn J. The effect of social network sites on adolescents' social and academic development: Current theories and controversies. J Am Soc Inf Sci . 2011; 62(8): 1435-45. doi: 10.1002/asi.21540.

4) Ahn J, Bivona LK, DiScala J. Social media access in K - 12 schools: Intractable policy controversies in an evolving world. Am Soc Inform Sci Annu Meet Proc. 2011; 48(1): 1-10. doi: 10.1002/meet.2011.14504801044.

5) McKibbon KA, Fridsma DB. Effectiveness of clinician-selected electronic information resources for answering primary care physicians' information needs. J Am Med Inform Assoc. 2006; 13(6): 653-9. doi: 10.1197/jamia.M2087. PMID: 16929042, PMCID: PMC1656967.

6) Keller B, Labrique A, Jain KM, Pekosz A, Levine O. Mind the gap: social media engagement by public health researchers. J Med Internet Res. 2014; 16(1): e8. doi: 10.2196/jmir.2982. PMID: 24425670, PMCID: PMC3906700.

7) Brown J, Ryan C, Harris A. How doctors view and use social media: a national survey. J Med Internet Res. 2014; 16(12): e267. doi: 10.2196/jmir.3589. PMID: 25470407, PMCID: PMC4275505.

8) Jahanshir A, Karimialavijeh E, Sheikh H, Vahedi M, Momeni M. Smartphones and Medical Applications in the Emergency Department Daily Practice. Emerg (Tehran). 2017; 5(1): e14. PMID: 28286821, PMCID: PMC5325882.

9) Moran M, Seaman J, Tinti-Kane H. Teaching, learning, and sharing: How today's higher education faculty use social media. Babson Survey Research Group. 2011.

10) Cheston CC, Flickinger TE, Chisolm MS. Social media use in medical education: a systematic review. Acad Med. 2013; 88(6): 893-901. doi: 10.1097/ACM.0b013e31828ffc23. PMID: 23619071. 
11) Eslaminejad T, Masood M, Ngah NA. Assessment of instructors readiness for implementing e-learning in continuing medical education in iran. Med Teach. 2009; 32(10): e407-12. doi: 10.3109/0142159X.2010.496006. PMID: 20854145.

12) Ashrafi-rizi H, Khorasgani ZG, Zarmehr F, Kazempour Z. A survey on rate of media literacy among Isfahan University of Medical Sciences' students using Iranian media literacy questionnaire. J Educ Health Promot. 2014; 3: 49. doi: 10.4103/2277-9531.131939. PMID: 25013842, PMCID: PMC4089109.

13) Sari-Motlagh R, Ebrahimi S, Nikfallah A, Hajebrahimi S, Shakiba B. Lifelong learning in practice: The age of discussion through social media. Eur Urol. 2016; 69(6): 1162-3. doi: 10.1016/j.eururo.2016.01.046.

14) Payne KB, Wharrad H, Watts K. Smartphone and medical related App use among medical students and junior doctors in the United Kingdom (UK): a regional survey. BMC Med Inform Decis Mak. 2012; 12: 121. doi: 10.1186/1472-6947-12-121. PMID: 23110712, PMCID: PMC3504572.

15) Bosslet GT, Torke AM, Hickman SE, Terry CL, Helft PR. The patient-doctor relationship and online social networks: Results of a national survey. J Gen Intern Med. 2011; 26(10): 1168-74. doi: 10.1007/s11606-011-1761-2. PMID: 21706268, PMCID: PMC3181288.

16) Kind T, Genrich G, Sodhi A, Chretien KC. Social media policies at US medical schools. Med Educ Online. 2010; 15. doi: 10.3402/meo.v15i0.5324. PMID: 20859533, PMCID: PMC2941429.

17) Odaci H. Academic self-efficacy and academic procrastination as predictors of problematic internet use in university students. Comput Educ. 2011; 57(1): 1109-13. doi: 10.1016/j.compedu.2011.01.005. 